\title{
Quantitative approach in iron oxides and oxihydroxides by vibrational analysis
}

\section{Aproximación cuantitativa en óxidos y oxihidróxidos de hierro mediante análisis vibracional}

\author{
A. F. Betancur(1, $\left.{ }^{*}\right)$ F. R. Pérez(1), M. del M. Correa(1), C. A. Barrero(2) \\ 1. Grupo de Óptica y Espectroscopía (GOE), Universidad Pontificia Bolivariana, A.A. 56006, Medellín, Colombia. \\ 2. Grupo de Estado Sólido (GES), Universidad de Antioquia, A.A. 1226, Medellín, Colombia. \\ (") Email: andresfebelo@gmail.com \\ Recibido / Received: 15/05/2012. Revisado / Revised: 18/07/2012. Aceptado / Accepted: 19/07/2012. \\ DOI: http://dx.doi.org/10.7149/OPA.45.3.269
}

\begin{abstract}
:
Four different mixtures of goethite, hematite and magnetite in different mass fraction percentage, were prepared. Raman and infrared spectroscopic measurements were carried out. For both sets of spectrum, mathematical relationships between the Raman and Infrared fraction, as obtained from the characteristic bands of each phase, and the respective mass fraction, were established. In most cases, linear relationships were obtained. A problem sample was used in order to estimate their respective relative phase abundances obtaining better results from the Raman spectroscopy measurements.
\end{abstract}

Key words: Infrared Spectroscopy, Raman Spectroscopy, Iron Oxides, Quantitative Analysis.

\section{RESUMEN:}

Se prepararon cuatro mezclas distintas de goethita, hematita y magnetita en diferentes porcentajes de fracción másica. Se realizaron medidas de espectroscopía Raman e infrarrojo. Para ambos conjuntos de espectros se obtuvieron relaciones matemáticas entre la fracción Raman y fracción Infrarroja, obtenidas estas a partir de las bandas características para cada fase, con su respectiva fracción másica. En la mayoría de los casos se obtuvieron relaciones lineales. Se usó una muestra problema para la estimación de las abundancias relativas obteniendo mejores resultados a partir de las medidas de espectroscopía Raman.

Palabras clave: Espectroscopía Infrarroja, Espectroscopía Raman, Óxidos de Hierro, Análisis Cuantitativo.

\section{REFERENCIAS Y ENLACES / REFERENCES AND LINKS}

[1]. R. M. Cornell, U. Schwertmann, The Iron Oxides, Willey-VCH Verlag GmbH \& Co., Weinheim (2003).

[2]. T. Nishimura, H. Katayama, K. Noda, T. Kodama, "Effect of Co and Ni on the corrosion behavior of low alloy steels in wet/dry environments", Corros. Sci. 42, 1611-1621 (2000).

[3]. F. R. Pérez, C. A. Barrero, O. Arnache, L. C. Sánchez, K. E. García, A. R. H. Walker, "Structural properties of iron phases formed on low alloy steels immersed in sodium chloride-richsolutions", Physica B 404, 1347-1353 (2009).

[4]. D. L. A. de Faria, S. V. Silva, M. T. Olivera, "Raman microspectroscopy of some iron oxides and oxyhydroxides", J. Raman Spectrosc. 28, 873-878 (1997).

[5]. H. Tamura, "The role of rusts in corrosion and corrosion protection of iron and steel", Corros. Sci. 50, 1872-1883 (2008). 
[6]. F. R. Pérez, C. A. Barrero, A. R. H. Walker, K. E. García, K. Nomura, "Effects of chloride concentration, immersion time and steel composition on the spinel phase formation", Mater. Chem. Phys. 117, 214223 (2009).

[7]. F. R. Pérez, C. A. Barrero, K. E. García, "Factors affecting the amount of corroded iron converted into adherent rust in steels submitted to immersion tests", Corros. Sci. 52, 2582-2591 (2010).

[8]. M. Yamashita, T. Shimizu, H. Konishi, J. Mizuki, H. Uchida, "Structure and protective performance of atmospheric corrosion product of Fe-Cr alloy film analyzed by Mössbauer spectroscopy and with synchrotron radiation X-rays”, Corros. Sci. 45, 381-394 (2003).

[9]. H. Namduriand, S. Nasrazadani, "Quantitative analysis of iron oxides using Fourier transform infrared spectrophotometry”, Corros. Sci. 50, 2493-2497 (2008).

[10].S. J. Oh, D. C. Cook, T. E. Townsend, "Characterization of iron oxides commonly formed as corrosion products on steel", Hyperfine Interact. 112, 59-65 (1998).

[11]. L. Legrand, G. Sagon, S. Lecomte, A. Chausse, R. Messina, "A Raman and infrared study of a new carbonate green rust obtained by electrochemical way", Corros. Sci. 43, 1739-1749 (2001).

[12]. H. D. Ruan, R. L. Frost, J. T. Kloprogge, L. Duong, "Infrared spectroscopy of goethite dehydroxylation. II. Effect of aluminium substitution on the behaviour of hydroxyl units", Spectrochim. Acta A 58, 479491 (2002).

[13]. F. Dubois, C. Mendibide, T. Pagnier, F. Perrard, C. Duret, "Raman mapping of corrosion products formed onto spring steels during salt spray experiments. A correlation between the scale composition and the corrosion resistance", Corros. Sci. 50, 3401-3409 (2008).

[14]. F. R. Pérez, C. A. Barrero, K. E. García, A. R. H. Walker, "Raman microscopy as a tool for the rust composition distribution analysis", Rev. Col. Fis. 42, 2, 187-190 (2010).

[15].X. Su, C. Yu, C. Qiang, "Synthesis of $\alpha-\mathrm{Fe}_{2} \mathrm{O}_{3}$ nanobelts and nanoflakes by thermal oxidation and study to their magnetic properties", Appl. Surf. Sci. 257, 9014-9018 (2011).

[16]. J. P. Labbé, J. Lédion, F. Hui, "Infrared spectrometry for solid phase analysis: Corrosion rustsm", Corros. Sci. 50, 1228-1234 (2008).

[17]. M. Gotic, S. Music, "Mössbauer, FT-IR and FE SEM investigation of iron oxides precipitated from FeSO solutions", J. Mol. Struct. 834-836, 445-453 (2007).

[18].S. A. Fysh, P. M. Fredericks, "Fourier transform infrared studies of aluminous goethites and hematites", Clay Miner. 31, 377-382 (1983).

[19]. J. Desai, H. M. Pathan, S. Min, K. Jung, O. Joo, "FT-IR, XPS and PEC characterization of spray deposited hematite thin films", Appl. Surf. Sci. 252, 1870-1875 (2005).

\section{Introduction}

The fields of application of iron oxides are tremendously wide. In a great number of processes including steels making, power generation, nuclear wastes disposal, pharmaceutical, cosmetic, petrochemical, corrosion steels among other, the comprehension of the formation and transformation of iron oxides is necessary [1]. In the case of corrosion, its methodological study contributed to understand the physical and chemical properties of their products, which is important to detect the evolution of rust layers in order to have a comprehension about its protective properties [2-3]. According to several authors, the understanding of the chemical and physical mechanisms involved in the oxidation reaction and the evolution and structure of the rust layer, is important to control the effects of corrosion [4-5].

The characteristics of the adherent rust layer formed on steels, such as composition, morphology and relative amounts, determine the resistance to corrosion. The precise determination of these relative amounts of each phase presented in rust is one important task for researchers from the corrosion workers $[6,7]$.

Standard methods for the identification and characterization of iron oxides have traditionally been X-ray diffraction (XRD) and/or Mössbauer spectroscopy (MS) [8]. MS technique has an operational disadvantage related to the manipulation of a radioactive source. In addition, measurements performed on several very low temperatures are necessary in order to properly 
differentiate magnetic and super-paramagnetic goethite and other phases. On the other hand, XRD is unable to differentiate between hematite and maghemite [9].

Due to the complexity of steel corrosion products, normally a combination of analytical techniques including Raman and infrared spectroscopies is commonly used [10,11]. However, a few of works address quantitative analysis. Infrared [9,12] and Raman spectroscopies $[13,14]$ have individually applied to estimate the relative amounts of iron phases on corrosion products. In this work, different combinations of goethite, magnetite and hematite were prepared varying their relative abundances. Measurements of Fourier Transform Infrared Spectroscopy (FT-IR) and Confocal Raman Microscopy (CRM) were performed. The correlations between the Raman or Infrared fraction of the most representative bands of all phases and their respective mass fraction were obtained. The results obtained by the two techniques are compared and discussed.

\section{Materials and methods}

\section{2.a. Experimental}

Analytical grade goethite, hematite and magnetite from Alpha Aeser were used. The samples were prepared by mixing of those three different iron oxide phases at different mass fractions. First, four different amounts of each phase were weighed with an analytical balance. They were mixed and ground in an agate mortar up to have a uniform color and finer powder. Finally, the samples were store in sealed bags up to be measured. The different samples have been labeled as S1, S2, S3 and S4 (See Table I).

FTIR spectra were carried out on a Nicolet 6700 FTIR in attenuated total reflection (ATR) mode by using a diamond crystal probe. With this crystal the optimal measurement range is between $650 \mathrm{~cm}^{-1}$ and $4200 \mathrm{~cm}^{-1}$. The collection was done for a 256 scans with a $4 \mathrm{~cm}^{-1}$ resolution. The Raman spectra were obtained by using a Horiba Jobin-Yvon Model LabRAM HR High Resolution, with the laser line of $632.81 \mathrm{~nm}$ and a 100X microscope objective. The spectra were collected at $120 \mathrm{~s}$ integration time and the nominal power into the sample was about 0.35 $\mathrm{mW}$.

Table I

Mass fraction percentage of four different combinations of goethite, hematite and magnetite.

\begin{tabular}{|c|c|c|c|}
\hline Sample & Goethite & Hematite & Magnetite \\
\hline S1 & 33.66 & 33.42 & 32.92 \\
\hline S2 & 74.94 & 15.42 & 9.63 \\
\hline S3 & 7.29 & 89.53 & 3.18 \\
\hline S4 & 17.92 & 11.34 & 70.74 \\
\hline
\end{tabular}

\section{2.b. Raman and infrared fraction}

Raman and infrared spectra from all mixing of iron oxides samples and from the pure phases were taken. Characteristic bands of each phase were selected by using not only the information presented in the literature [1,4,6-9] but also our measurements. As it was expected, all the bands in the spectra coming from the different mixing showed different relative intensities at different concentrations. In order to establish a relationship between the band intensities of each phase and their respective concentration, we proceeded as it is explained. First, the total intensity for a phase was defined as:

$$
I_{i}=\sum_{j=1}^{k} I_{j},
$$

where $I_{j}$ is the intensity of the $j$ characteristic band corresponding to a specific phase. The label $k$ is the number of those characteristics bands. In other words, $I_{i}$ is the sum of all $I_{j}$ $(j=1, \ldots, k)$ intensities of the selected bands for the phase $i$. Here, the label i stands for goethite, magnetite or hematite $(i=1, \ldots, n)$. Then, the infrared or Raman fractions, $f_{i}$, was defined dividing $I_{i}$ by the summation of $I_{i}$ taken on all the $n$ phases. In this work, $n=3$, i.e. goethite, hematite and magnetite, respectively. In this way, the Raman (or infrared) fraction of the $i$ phase was calculated as it follows:

$$
f_{i}=\frac{I_{i}}{\sum_{i=1}^{n} I_{i}} .
$$

It is good to say that the intensities used in this procedure are normalized as it will be explained in Section 3.c. 
Different factors like crystallinity, particle size, temperature, instrumental noise and nanometric structure, among other, could affect the vibrational characteristics of a material. Hence, the procedure to estimate the relative abundances of each phase, are not a simple task. In this work we propose that $f_{i}$ in Eq. (2) could be a function of therelative abundances under the supposition that is the concentration the property that more hardly affects the spectral intensity.

\section{Results and discussion}

A brief description of the major infrared and Raman bands of the iron phases used in this paper is presented. Hence, based on results reported for different authors, the experimental bands were chosen.

\section{3.a. Raman spectroscopy (CRM)}

The most representative bands of hematite are around $228.6 \mathrm{~cm}^{-1}$ and $295.02 \mathrm{~cm}^{-1}$. According to Faria et al. [4], these bands of hematite are two of the seven Raman active phonons. These two bands were taken for quantitative analysis. The remaining five phonon bands at about 247.9, $300.9,413.8,500.2$ and $614.5 \mathrm{~cm}^{-1}$ [4], all of them were found in our spectrum. From the literature, the band at about $1317.8 \mathrm{~cm}^{-1}$ is a vibration which has some unclear origin. Faria et al. [4] says that this band is caused by the scattering of two magnons in the structure, but according to $\mathrm{Su}$ et al. [15], this phonon consists in a second harmonic vibration. It is important to say that the band of hematite at $1317.8 \mathrm{~cm}^{-1}$ is close to the magnetite at approximately 1304.9 $\mathrm{cm}^{-1}$. This causes an overlapping in vibrations when these two phases are mixed, making difficult their identification by using those bands. Therefore, these bands were not selected as analytical bands of hematite and magnetite. The band of goethite that stands out over other active modes in Raman spectra is $388.8 \mathrm{~cm}^{-1}$. The band at about $552.3 \mathrm{~cm}^{-1}$ does not appear in the other analysed phases, therefore, it was used for the development mathematical fitting. In the case of magnetite, the most representative band is found at about $667.2 \mathrm{~cm}^{-1}$, hence we selected it as the analytical band. The other bands cannot be selected, because they interfere with bands from the other phases $[4,15]$.

\section{3.b. Infrared spectroscopy (FT-IR)}

The quantification of iron oxides by infrared spectroscopy is not common, although a good number of qualitative studies are found in literature [4,6,7]. Recently, proposals to use infrared [9] and Raman spectroscopy [13] in quantitative studies on iron oxides have been reported. According to Gotic and Music [17], the IR band at $3144 \mathrm{~cm}^{-1}$ can be assigned to the $\mathrm{OH}$ stretching mode in the goethite structure $(\alpha-$ $\mathrm{FeOOH}$ ). Therefore, this vibration cannot be selected as a characteristic band of goethite. Most of authors agree the major bands of goethite are at about $793 \mathrm{~cm}^{-1}$ and $898 \mathrm{~cm}^{-1}$ $[1,17]$. In this way, the analytical bands selected were those found at $792.6 \mathrm{~cm}^{-1}$ and $896.7 \mathrm{~cm}^{-1}$. In magnetite and hematite mixing, the differentiation of their bands is difficult by infrared measurements. This is due to their characteristics vibrations are close. Namduri et al. [9] assigned the bands at $540 \mathrm{~cm}^{-1}$ and 570 $\mathrm{cm}^{-1}$ as analytical bands of hematite and magnetite, respectively. Fysh and Fredericks [18] working with hematite at high temperature, reported bands at 470 and $550 \mathrm{~cm}-1$. Desai et al. [19] showed bands of hematite at 476 and 616 $\mathrm{cm}^{-1}$. Gotic and Music [17] reported bands at 360 $\mathrm{cm}^{-1}$ and $565 \mathrm{~cm}^{-1}$ for magnetite. Labbé et al. [16] reported a band at $570 \mathrm{~cm}^{-1}$ as the major band of magnetite. In this work, the bands used were those at $416 \mathrm{~cm}^{-1}$ and $430 \mathrm{~cm}^{-1}$ for hematite, and $570 \mathrm{~cm}^{-1}$ for magnetite.

\section{3.c. Combined phases: Raman (CRM) and Infrared (FT-IR) measurements}

Figures 1 to 4 show the CRM and FT-IR spectra from the iron phase mixtures, respectively. No fitting were performed on the spectra. However, in order to minimize the effect of the baseline on the data, all spectra were normalized by using the following equation:

$$
N_{i}=\frac{x_{i}-I_{\min }}{I_{\max }-I_{\min }}
$$

where $N_{i}, x_{i}, I_{\max }$ and $I_{\min }$ stands for the normalised, the absolute, the maximum absolute and minimum absolute intensity, respectively of all spectrum. 
It is clear that the intensity changed with the mass fraction percentages in all cases. In both techniques the appearance of each spectrum is consistent with the data showed in Table I. In Fig. 1(A), bands associated to the three phases have relative intensities which are comparable between them. This result is in good agreement with the respective phase abundance (sample S1). The sample S2 has $74.94 \%$ in mass fraction of goethite which is the reason of the predominance of its spectrum over the other ones showed in Fig. 1(B). The same can be said in relation to Fig. 2(C) and 2(D) related with hematite and magnetite, respectively which were the most abundant phase in each case.

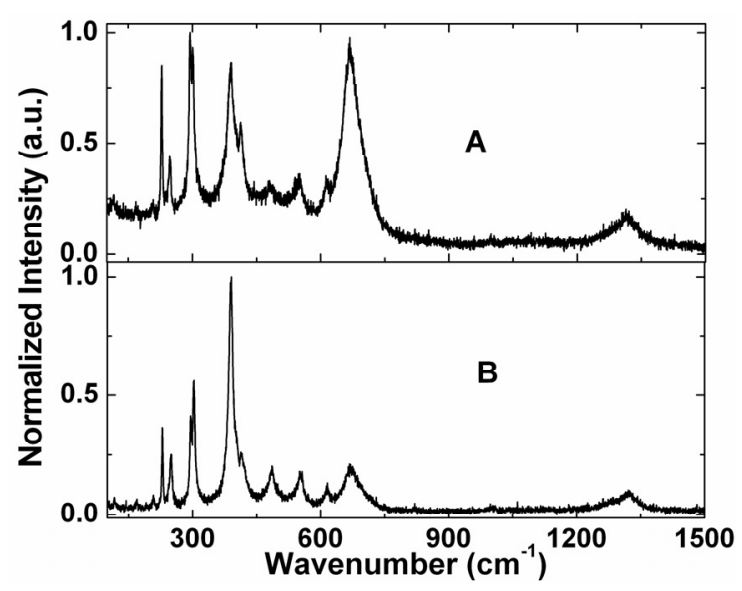

Fig. 1. Raman spectra from the mixtures of hematite, goethite and magnetite: S1 (A) and S2 (B).

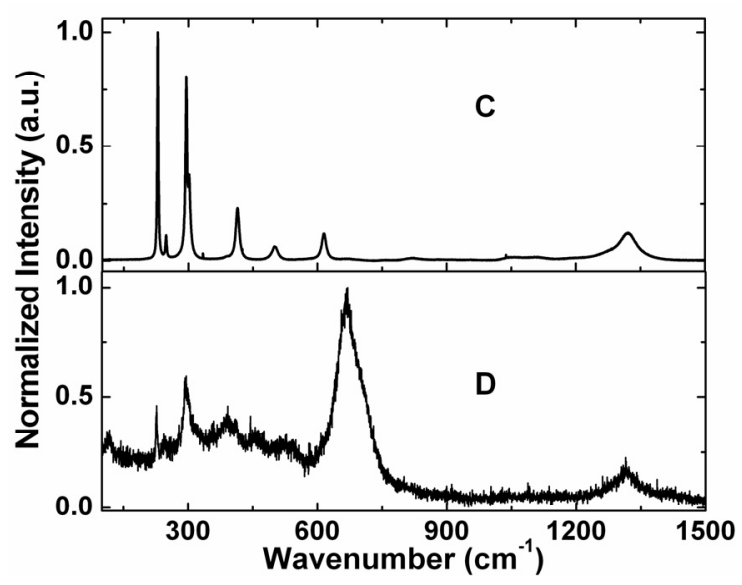

Fig. 2. Raman spectra from the mixtures of hematite, goethite and magnetite: S3 (C) and S4 (D).
Although the analysis before presented for CRM may be some less evident for hematite and magnetite than for goethite in FT-IR spectra (see Figs. 3 and 4), a detailed observation can show a similar behavior.

After the analytical bands of each iron phase were selected and the respective Raman and infrared fraction determined, relations between the Raman and infrared fraction and the respective mass fraction were obtained. Table II and III show the corresponding Raman or infrared fraction $\left(f_{R}\right.$ or $\left.f_{I}\right)$ as a function of the mass fraction percentage $(w)$ for all phases, and for both CRM or FT-IR, respectively. In addition the regression equations are presented. All the fittings are lineal. The respective correlation coefficients are shown in Table II and III as well. These could be better if more experimental data were used.

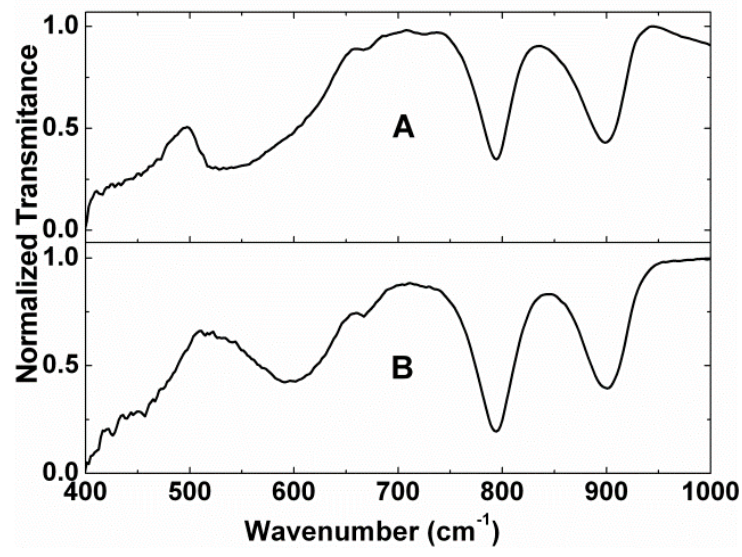

Fig. 3. Infrared from the mixtures of hematite, goethite and magnetite: S1 (A) and S2 (B).

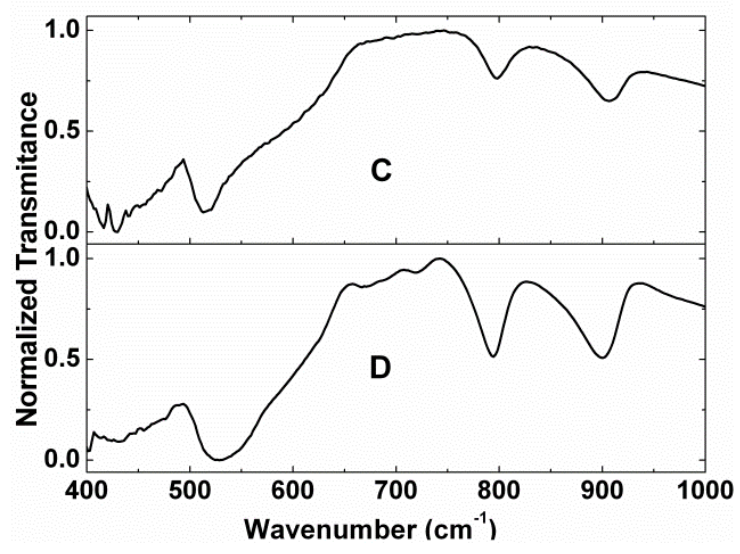

Fig. 4. Infrared from the mixtures of hematite, goethite and magnetite: S3 (C) and S4 (D). 
Table II

Raman fraction $\left(f_{R}\right)$ as a function of mass fraction percentage $(w)$ for three different iron phases mixing obtained from CRM measurements.

\begin{tabular}{|c|c|c|}
\hline \multicolumn{3}{|c|}{ CRM } \\
\hline Phase & Fitting Equation & $\mathbf{R}^{\mathbf{2}}$ \\
\hline Goethite & $f_{R}=0.0069 w+0.0528$ & 0.8789 \\
\hline Hematite & $f_{R}=0.0083 w+0.2282$ & 0.9878 \\
\hline Magnetite & $f_{R}=0.0055 w+0.0201$ & 0.9589 \\
\hline
\end{tabular}

Table III

Infrared fraction $\left(f_{I}\right)$ as a function of mass fraction percentage $(w)$ for three different iron phases mixing obtained from FT-IR measurements

\begin{tabular}{|c|c|c|}
\hline \multicolumn{3}{|c|}{ FT-IR } \\
\hline Phase & Fitting Equation & $\mathbf{R}^{2}$ \\
\hline Goethite & $f_{I}=0.1198 \ln (w)-0.1058$ & 0.9881 \\
\hline Hematite & $f_{I}=0.0028 w+0.4504$ & 0.8096 \\
\hline Magnetite & $f_{I}=0.0011 w+0.1373$ & 0.8745 \\
\hline
\end{tabular}

In order to evaluate our methodology, a sample having known concentrations (problem sample), was prepared (S5). The actual concentrations in S5 were compared to the concentrations obtained from the fitting equations (see Tables II and III) in both CMR and FT-IR. The comparisons are shown in Tables IV and $\mathrm{V}$.

The error in the estimated relative abundances obtained from the Raman measurements were below $20 \%$ for all the three phases. In contrast, in the infrared measurements, the only error less 20\% corresponded to magnetite. This could be explained by the following reason: the most important vibrational mode of hematite is less than $650 \mathrm{~cm}^{-1}$ being out of the optimal operating range of our FT-IR equipment $\left(650 \mathrm{~cm}^{-1}, 4200\right.$ $\mathrm{cm}^{-1}$ ). Better results could be obtained if a FT-IR equipment working in the range between 400 $\mathrm{cm}^{-1}$ and $10 \mathrm{~cm}^{-1}$ were used.

The correlations between Raman or infrared fraction and the respective relative mass fraction (fitting equations) have small value in the variability, $\mathrm{R}^{2}$, except in the cases of hematite in the CMR data and goethite in the FT-IR data. Those variability coefficients, $\mathrm{R}^{2}$, were 0.9878 and 0.9881 , respectively. In addition, if the characteristic bands are not precisely
Table IV

Comparison of the calculated and actual relative abundance by using Raman measurements (CRM)

\begin{tabular}{|c|c|c|c|c|}
\hline \multirow{2}{*}{ Phase } & S5 & \multicolumn{2}{|c|}{$\begin{array}{r}\text { Concentration } \\
(w)\end{array}$} & \multirow{2}{*}{$\%$} \\
\cline { 2 - 4 } & $\begin{array}{c}\text { Raman } \\
\text { fraction }\left(f_{R}\right)\end{array}$ & $\begin{array}{c}\text { Cal. } \\
\%\end{array}$ & $\begin{array}{c}\text { Actual } \\
\%\end{array}$ & Error \\
\hline Goethite & 0.22 & 24.84 & 30.07 & 17.4 \\
\hline Hematite & 0.65 & 51.13 & 48.31 & 5.9 \\
\hline Magnetite & 0.12 & 18.74 & 21.62 & 13.3 \\
\hline
\end{tabular}

TABLE V

Comparison of the calculated and actual relative abundance by using infrared measurements (FT-IR)

\begin{tabular}{|c|c|c|c|c|}
\hline \multirow{2}{*}{ Phase } & \multirow{2}{*}{$\begin{array}{c}\text { S5 } \\
\text { Infrared } \\
\text { fraction }\left(f_{I}\right)\end{array}$} & \multicolumn{2}{|c|}{$\begin{array}{c}\text { Concentration } \\
(w)\end{array}$} & \multirow{2}{*}{$\begin{array}{l}\% \\
\text { Error }\end{array}$} \\
\hline & & $\begin{array}{c}\text { Cal. } \\
\%\end{array}$ & $\begin{array}{c}\text { Actual } \\
\% \\
\end{array}$ & \\
\hline Goethite & 0.33 & 37.70 & 30.07 & 25.4 \\
\hline Hematite & 0.51 & 21.94 & 48.31 & 54.6 \\
\hline Magnetite & 0.16 & 19.85 & 21.62 & 8.2 \\
\hline
\end{tabular}

established for a phase, the respective estimated concentrations are significantly deviated from the actual value. Finally, it is observed when the variability coefficient, $\mathrm{R}^{2}$, has a value less than 0.9 , the estimated concentration is less than the real one.

\section{Conclusions}

Raman and infrared spectroscopic measurements on different mixtures of goethite, hematite and magnetite were performed. Qualitative correspondences between the appearances of all spectra and the relative abundance of each phase were discussed. Following a simple procedure, mathematical relations between the Raman or Infrared fraction of each phase characteristic bands, and the respective mass fraction percentage, were obtained. The quality of the fitting equations could be improved by increasing the number of points. The results suggest that infrared and Raman spectroscopy can be applied as methods for qualitative as well as quantitative analyses. In order to use and improve the methodology for determining the relative abundances of iron oxide phases in the corrosion products from steel, it should be prepare mixtures containing 
other iron phases like akaganeite, lepidocrocite, among others.

\section{Acknowledgements}

The authors acknowledge the support of the SIU from Universidad de Antioquia, CIDI, GIA and GINUMA research groups from Universidad Pontificia Bolivariana. Finally, thanks go to Colciencias for the financial support to A. F. Betancur by a Beca de Joven Investigador (20102011). 